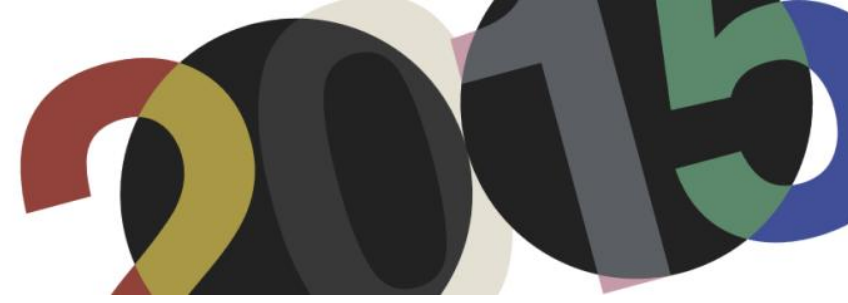

DOI: http://dx.doi.org/10.4995/LC2015.2015.824

\title{
Le Corbusier versus Sergei Eisenstein. La construcción de un sueño
}

\author{
E. Martínez Millana
}

\author{
Escuela Superior de Arquitectura de Madrid
}

\begin{abstract}
Resumen: Este artículo plantea la revisión de la relación entre el arquitecto Le Corbusier y el cineasta Sergei Eisenstein. Se lanza como hipótesis la posible influencia del cineasta en Le Corbusier. Le Corbusier versus Eisenstein en el sentido más profundo de 'avanzar en dirección a': Le Corbusier hacia la cinematografía, no como contraposición. Se esboza el papel de cada figura y su encuentro en el período de 1928-1936, tiempo en que Le Corbusier se aproximó a la Unión Soviética, un contexto que configura un marco complejo a partir del cual es posible entrever aquello que los vincula y que refuerza la hipótesis planteada. Por otro lado, se realiza un análisis de Poème électronique - filme de 480" que Le Corbusier hace en 1958 con motivo de la Exposición Universal en Bruselas - con la intención de visibilizar que Le Corbusier recurre a la técnica del montaje dialéctico de la que Eisenstein era maestro y por tanto la consustancial influencia. Le Corbusier reconoce el potencial de esta técnica de montaje y se sirve de ella como la estrategia clave en su aproximación al ámbito de la cinematografía. El mecanismo del montaje dialéctico forma parte de su propio pensamiento y lo materializa en su arquitectura y también en el caso de estudio que nos ocupa, en la disciplina de la imagen en movimiento, tan próxima a ésta. Pero hay más, en el Pabellón Philips la técnica del montaje oculto - sobre la que Eisenstein había teorizado en aquél periodo - está presente, pues mediante éste mecanismo construye la puesta en escena del espectáculo total. Como veremos, Poème électronique representa la construcción de un sueño.
\end{abstract}

Abstract: This article reviews the relationship between the architect Le Corbusier and the filmmaker Sergei Eisenstein. When launched, it was seen to hypothesise the possible influence of the filmmaker in the work of Le Corbusier. Le Corbusier versus Eisenstein, in the deepest sense of the expression, is portrayed as "towards to": Le Corbusier towards the film, not in opposition to it. It outlines the role of each figure and their interactions during the period between 1928 and 1936, the time when Le Corbusier got closer to the Soviet Union. This context forms a complex framework from which it is possible to glimpse what it is that links them, reinforcing the hypothesis-raised. On the other hand, this work presents an analysis of the Poème électronique - 480" film Le Corbusier made in 1958 for the Universal Exhibition in Brussels - in order to exemplify that Le Corbusier uses the technique of dialectical montage, in which Eisenstein was the undisputed master, thereby highlighting an inherent influence. Le Corbusier recognises the potential of this montage technique and uses it as a key strategy in his approach to the field of cinema. The mechanism of dialectical montage is a part of Le Corbusier's own thought and this materialises both in his architecture as well as in the subsequent case study regarding the discipline of the moving image, which is closely aligned to it. There is, however, more to it. In the Philips Pavilion, the hidden montage technique theorised by Eisenstein in that period - is present, the use of which was the mechanism to construct the stage for the spectacle as a whole. As we will see, Poème électronique represents the construction of a dream.

Palabras clave: Eisenstein; Le Corbusier; Le Poème électronique; montaje dialéctico; montaje oculto; cinematografía. Keywords: Eisenstein; Le Corbusier; Le Poème électronique; dialectical montage; hidden montage; cinematography.

\section{Introducción}

¿Por qué La construcción de un sueño? porque construcción implica técnica, y en este caso se trata del montaje; le sigue sueño, pues implica utopía. Le Corbusier y Sergei Eisenstein comparten esta manera de trabajar, ambos con el firme objetivo de comunicar experiencia. 
El presente trabajo tiene por objetivo la revisión de la relación entre el arquitecto y el cineasta. La investigación, sobre los vínculos que existen entre ambas figuras, ya ha sido emprendida anteriormente por otros autores ${ }^{1}$ desde el punto de vista trans*disciplinar, asociando las disciplinas propias de cada personaje. Se retoman las publicaciones al respecto con la intención de avanzar en la indagación de estas conexiones, y se lanza como hipótesis la posible influencia del cineasta en Le Corbusier. Le Corbusier versus Sergei Eisenstein en el sentido más profundo de 'avanzar en dirección a': Le Corbusier hacia la cinematografía. No como contraposición.

Con esta investigación se visibiliza que las teorías de Eisenstein están presentes en el filme Poème électronique, que Le Corbusier elabora con motivo de la Exposición Universal en Bruselas, en 1958. Reconoce el poder de este mecanismo de representación de la realidad, y la fuerza con que un mensaje puede transmitirse, precisamente por la capacidad que tiene de activar al espectador, e involucrarlo en la construcción de su significado. Por otro lado, no se obvia que el filme forma parte de la boîte à miracles del Pabellón Philips, un contenedor-substancia en el que están presentes también las teorías sobre el montaje que desarrolló el cineasta.

\section{Metodología}

Tras la hipótesis expuesta, la investigación se estructura fundamentalmente en dos bloques: el marco teórico y el caso de estudio.

En el primer bloque, se esboza el papel de cada figura y su encuentro en el período de 1928-1936. En el segundo bloque, se toma como caso de estudio el filme Poème électronique, y se incorporan los aspectos que permiten una más profunda comprensión del espectáculo del que forma parte, el lugar en el que se proyectó. El Pabellón Philips pudo suponer una respuesta a los presupuestos que Le Corbusier aprendió de Eisenstein. Este trabajo indaga sobre las teorías del cineasta en el periodo en que se conocieron, en concreto, sobre un par clave que visibiliza la posible influencia de Eisenstein en Le Corbusier: montaje dialéctico y montaje oculto.

\section{Resultados. Cuerpo del trabajo}

\subsection{Arquitectura y cinematografía desde el montaje}

En este primer bloque se indaga sobre el papel de Le Corbusier y Sergei Eisenstein, acotado en el período de tiempo entre 1928-1936, tiempo en que ambos propusieron teorías y proyectos que, desde sus disciplinas, trataban de construir una Unión Soviética tras la Revolución de 1917.

\subsubsection{Le Corbusier y Sergei Eisenstein}

El período en que Le Corbusier tendió puentes con la URSS se inicia con su visita a Moscú en Octubre de 1928; tiempo en que pudo conocer de primera mano la deriva de la Revolución de 1917. En aquel viaje conoció a Sergei Eisenstein, vio El acorazado Potemkin (1925) y cuatro rollos de Lo viejo y lo nuevo (1929). Le Corbusier concedió una entrevista en la que expresaba su admiración por el cineasta:

"La arquitectura y el cine son las dos únicas artes de nuestro tiempo. Creo pensar en mi propio trabajo como lo hace Eisenstein en sus películas. Sus trabajos penetran únicamente en la verdad. Sólo dan prueba de la realidad. Sus ideas, sus películas se parecen mucho a lo que me estoy esforzando por hacer en mi propio

\footnotetext{
1 Martínez de Guereñu, Laura: Montage: "Le Corbusier y Eisenstein”. En: Massilia 2008. Anuario de estudios Lecorbusierianos. Granada: Colegio de Arquitectos de Granada, 2008.pp.242-255
} 
trabajo. Su insistencia en lo esencial no sólo realza su trabajo por encima de la mera narrativa, sino que eleva los acontecimientos cotidianos que escapan de nuestra atención superficial al nivel de imágenes monumentales",

Los textos de Le Corbusier pueden estudiarse de forma paralela a los de Eisenstein. El mismo año en que Le Corbusier publicó Vers une Architecture (1923), Eisenstein escribió Montage of Attractions ${ }^{3}$. Le Corbusier hacía referencia al "gran director de escena" de los edificios de la Acrópolis de Atenas:

"El desorden aparente del plan sólo engaña al profano. El equilibrio no es mezquino. Está determinado por el famoso paisaje que se extiende desde el Pireo al Monte Pentélico. El plan está concebido para su visión lejana: los ejes que siguen el valle y las falsas escuadras son habilidades del gran director de escena. La Acrópolis sobre su roca y sus muros de sostén, se ve desde lejos, en forma total. Sus edificios se amontonan en la sucesión de sus múltiples planos",

Fue en Hacia una Teoría del Montaje (1937), en el capítulo "Montaje y arquitectura", en donde Eisenstein empleó el mismo ejemplo que utilizó Le Corbusier en Hacia una arquitectura: la Acrópolis de Atenas; con este ejemplo, el cineasta vinculaba las teorías de montaje que él desarrollaba en el cine con la arquitectura,

"Sólo la cámara cinematográfica ha resuelto el problema de hacerlo (representar la multidimensionalidad visual) en una superficie plana, pero su antecesor ineludible con esta capacidad es la arquitectura. Los griegos nos han dejado los ejemplos más perfectos de diseño del plano, cambio de plano y duración del plano" ${ }^{, 5}$

Eisenstein incluyó, en este capítulo, numerosas perspectivas y plantas que Auguste Choisy publicó en Histoire de l'Architecture ${ }^{6}$, y escribió "es difícil imaginar una secuencia de montaje de un conjunto arquitectónico con una composición más sutil, plano a plano, que la que crean nuestras piernas paseando entre los edificios de la Acrópolis" "7. Le Corbusier también las utilizó en Hacia una Arquitectura.

Le Corbusier y Eisenstein, desarrollaban, de forma consciente y en paralelo, los mismos presupuestos; y, en este caso, se valieron del mismo ejemplo e ilustraciones para, desde la teoría expuesta en sus publicaciones, comunicar sus ideas.

\subsubsection{Montaje, cinematografía y revolución. Sergei Eisenstein.}

Resulta interesante detenerse en la dimensión de las teorías de Sergei Eisenstein, sobre el montaje en la cinematografía, en el período en que Le Corbusier visitó Moscú. Las claves de éstas ya estaban en las clases que

\footnotetext{
2 "Architecture and the cinema are the only two arts of our time. In my work I seem to think as Eisenstein does in his films. His work is shot through with the sense of truth, and bears witness to the truth alone. In their ideas, his films resemble closely what I am striving to do in my work. This insistence on essentials not only raises his work above mere narrative, bus also raises the everyday events that escape our superficial attention to the level of monumental images" Cohen, Jean-Louis: Le Corbusier and the mystique of the URSS: Theories and projects for Moscow 1928-1936. Princeton, New Jersey: Pinceton University Press, 1992.pp.48-49

${ }^{3}$ Apareció publicado, por primera vez, en la revista LEF: Levy Front Iskusstv (Frente de Izquierda de las Artes), en 1923.

${ }^{4}$ Le Corbusier: Hacia una arquitectura. Barcelona: Apóstrof, 1998.p.39

${ }^{5}$ Eisenstein, Sergei: Hacia una teoria del montaje. Vol.1. Barcelona: Paidós Ibérica, 2001.pp.87-109

${ }^{6}$ Choisy, Auguste: Histoire de l'Architecture. París: Baranger, 1899.p.330

${ }^{7}$ Eisenstein, Sergei: Hacia una teoria del montaje. Vol.1. Barcelona: Paidós Ibérica, 2001.p.89
} 
impartía en la Facultad de Dirección Cinematográfica (VGIK) en Moscú; en 1928-1929, impartió un curso, a modo de laboratorio, sobre dirección, y empezó como profesor oficial en 1932.

Las dos publicaciones que hizo sobre sus clases, El Granito de la ciencia cinematográfica (1933), más tarde reemplazado por Programa de Enseñanza (1936), reflejan "su firme determinación de comunicar todo lo que sabia"». En palabras de Eisenstein, "el aspecto más importante no es exponer la solución, sino el método". Durante estos años de enseñanza, entre 1932-1935, el trabajo de Eisenstein "se caracterizaba por la exploración de nuevas posibilidades docentes y sus lecciones constituían una especie de revisión creadora del programa proyectado $^{, 10}$.

Resulta significativo que construyera el desarrollo de la clase como un coloquio, concediendo a los alumnos un papel activo en este proceso, en el que él "utilizaba la discusión de un nuevo problema como preparación para su propia solución, obtenida antes trabajosamente" "11. Eisenstein, desempeña el papel del autor productor, "La mejor opinión de nada sirve si no induce a quienes la albergan a hacer algo útil",12; y, como señala Shklovski, "el artista tiene derecho a un cierto número de libertades en su relación con el material de la vida, libertad de escoger, de cambiar, de rechazar. Eisenstein sabe servirse de las cosas" ${ }^{\prime \prime}$. Desde la teoría, la docencia y su obra: enseña el mecanismo, utilizándolo.

En la recopilación de sus Lecciones, el primer bloque agrupa la puesta en escena y la división de planos, pues "La puesta en escena contiene en si misma todos los elementos relacionados con la división y el montaje de planos"”; ; y, el segundo, la organización en el plano. Eisenstein los denomina así: "Si mise-en-scène significa puesta en escena, la ordenación de la escena; llamemos a la organización del plano mise-en-plan" "I5. Este par de mecanismos de montaje: la división de la acción en planos, y proyecto y planteamiento de la acción en un plano, es clave en la relación que se establece aquí entre Le Corbusier y Eisenstein.

\section{*La puesta en escena y la división de planos. El montaje dialéctico [ Mise-en-scène ]}

Para Eisenstein, el montaje abarca todos los aspectos de la producción del filme, y contiene operaciones como el planteamiento de la puesta en escena. Ésta ocupaba un lugar esencial en sus ideas, es "la determinación de los detalles de la acción para fines de representación, incluyendo, principalmente, la posición de los actores en los diferentes lugares, su movimiento en el espacio determinado por el decorado, la determinación del decorado para adecuarse a la acción "16.

Hasta aquí, propone una construcción de la puesta de escena que es común en el teatro y la cinematografía: la acción se divide en escenas, y las escenas en puestas de escena; el aspecto clave lo plantea cuando trasciende los

\footnotetext{
${ }^{8}$ Esta segunda versión está incluida en la recopilación que hizo un discípulo suyo, Vladimir Nizhny, a partir de los estenogramas de las clases del curso y las notas separadas que Nizhny tomó, especialmente de todos los dibujos hechos por Eisenstein que se conservan en el Archivo Eisenstein y en los archivos en el Instituto Cinematográfico (VGIK). Nizhny, Vladimir: Lecciones de cine de Eisenstein. Barcelona: Seix Barral, 1963.p.238

${ }^{9}$ Ibíd.p. 163

${ }^{10}$ Ibíd.p. 165

${ }^{11}$ Ibíd.p. 236

${ }^{12}$ Benjamin, Walter: El autor como productor. Madrid: Casimiro, 2015.p.28. Este texto se publica póstumamente a partir del manuscrito que preparó para una ponencia que no llegó a dar en París, 1934.

${ }^{13}$ Shklovski, Viktor: Eisenstein. Barcelona: Anagrama, 1973.

${ }^{14}$ Nizhny, Vladimir: Lecciones de cine de Eisenstein. Barcelona: Seix Barral, 1963.p.233

${ }^{15}$ Ibíd.p. 233

${ }^{16}$ Ibíd.p. 276
} 
límites del teatro, pues allí comienza el cine, "en el cine la división va más allá, cada puesta la escena se divide aún en unidades de montaje y la unidades de montaje en planos" "17. Eisenstein emplea el montaje desde el planteamiento y a lo largo de todo el desarrollo del proyecto.

Resulta interesante que Tafuri y Deleuze escribieran, al tiempo, sobre esta cuestión. Ambos destacaron la idea del plano del montaje como célula.

Tafuri, en La esfera y el laberinto (1980), recogió esta cita de Eisenstein: "El encuadre es una célula de montaje. Exactamente igual que las células nacen por división, originando un fenómeno de otro orden, el organismo o embrión, así, en otro extremo del salto dialéctico del encuadre, nos encontramos con el montaje. ¿Pero qué es lo que caracteriza al montaje y por tanto su célula o encuadre? El choque. El conflicto de dos fragmentos opuestos uno al otro" ${ }^{\text {"18. }}$.

Deleuze, en La imagen movimiento (1983), describió el montaje como un organismo destacando la analogía del plano como célula; y recogió el reproche que Eisenstein hizo a Griffith por no considerar la fuerza motriz por la cual la unidad dividida vuelve a formar una unidad nueva, "como unidad de producción, célula que produce sus propias partes por división, por diferenciación" $" 19$.

Tafuri lo describe como estallido, explosión del encuadre, y explica que "Eisenstein extrae el fotograma estático, fuerza el fotograma ideal a participar en la continuidad dinámica y temática, transfiguración extática provocada por la explosión, tiene por ello este primer significado, multiplica los significados potenciales”; y también subraya como precipita la imaginación del espectador , "es precisamente la fragmentación de los medios expresivos, el enfrentamiento con las leyes relativas a la estructura del organismo, y la desintegración de los elementos formales, lo que él hace precipitar con su imaginaria explosión "20.

Eisenstein, sobre el papel del espectador, describe en el artículo "Montaje de atracciones", publicado en la revisa soviética LEF (1923),

"Este método determina radicalmente las posibilidades de desarrollar una puesta en escena "activa"(el espectáculo es su conjunto): en lugar de ofrecer una "reproducción” estática del acontecimiento dado, exigido por el tema (...) se propone un nuevo procedimiento: el libre montaje de acciones (atracciones)" ${ }^{21}$.

Lo describió con mayor precisión, en “Montaje”(1938), más tarde denominado "Palabra e imagen”,

"Su eficacia reside en que incluye en el proceso creador las emociones e inteligencia del espectador. Quien es obligado a marchar por el mismo camino creador recorrido por el autor al crear la imagen. El espectador ve no sólo los elementos representativos de la obra ya terminada, sino que vive también el proceso dinámico de la aparición y composición justamente como fue vivido por el autor (...) el espectador es arrastrado hacia un acto

\footnotetext{
${ }^{17}$ Ibíd.p. 142

${ }^{18}$ Eisenstein, Sergei: "Il principio cinematográfico e l'ideogramma". En: Forma e técnica, 1929.p.36, citado en Tafuri, Manfredo: La esfera y el laberinto. Vanguardias y arquitectura. De Piranesi a los años setenta. Barcelona: Gustavo Gili, 1984.p.93

${ }^{19}$ Deleuze, Gilles: La imagen movimiento. Barcelona: Paidós, 2014.p.56

${ }^{20}$ Tafuri, Manfredo: La esfera y el laberinto. Vanguardias y arquitectura. De Piranesi a los años setenta. Barcelona: Gustavo Gili, 1984.p.90

${ }^{21}$ Eisenstein, Sergei: Reflexiones de un cineasta. Barcelona: Lumen, 1970.p.314
} 
creador en el cual su individualidad no está subordinada a la del autor, sino que se descubre a través del proceso de fusión con la intención de aquél ${ }^{, 22}$.

El objetivo fundamental de Eisenstein es la comunicación con las masas a través de este arte, útil. Empleó el cine como medio y el montaje como técnica principal. Le Corbusier reconoce el potencial de las teorías de montaje del cineasta, precisamente por la capacidad que tiene de activar al espectador e involucrarlo en la construcción de su significado. Estos mecanismos los incorporó en su propio pensamiento y los materializó en su arquitectura, así como en su aproximación al ámbito de la cinematografía.

\section{*La organización dentro del plano. El montaje oculto [ Mise-en-plan ]}

La otra técnica de montaje que enseñaba en sus clases, consistía en la puesta en escena dentro de los límites de un plano: con una única posición y un solo ángulo de la cámara, y sin dividir la escena en planos. A este mecanismo lo denominó "montaje oculto",23.

En ambos mecanismos de montaje: mise-en-plan y mise-en-scène, Eisenstein explica que "el montaje interviene cuando el plano estalla, cuando la pantalla estalla. Cuando la tensión dentro de un plano alcanza sus límites y no puede crecer más el espacio del plano, entonces estalla, dividiéndose en trozos, unidades de montaje" ${ }^{24}$.

Eisenstein defendió la analogía entre la historia del desarrollo del espacio escénico en una representación teatral y la transición del plano al montaje. Sobre la cuestión de la unidad del espacio escénico, en el período barroco, aunque las decoraciones, por lo general, no variaban, explicaba que "trataron de desarrollar un espacio de representación escénica unificado de tal forma que, dentro de la decoración única, pareciera que una serie de construcciones se sucedían unas a otras ${ }^{, 25}$.

Para Eisenstein, el mise-en-plan radica en que "el plano y el montaje no pueden contraponerse uno a otro como esferas diferentes, sino como fases de una sola y única operación, como un salto dialéctico de la cantidad a la calidad. Hay casos en que se puede presentar la acción dentro de un plano con la misma saturación dinámica que por medio del montaje” ${ }^{26}$. En las clases, y de forma extensa en un artículo ${ }^{27}$, se refirió a los grabados de Piranesi para ejemplificar esta cuestión. El montaje oculto opera en un plano que no tiene límites.

Esta técnica de montaje oculto, Eisenstein, la teorizaba y materializaba en sus películas en el período en que conoció a Le Corbusier. Resulta significativa la analogía de este mecanismo en ambas disciplinas, Le Corbusier se pudo servir de ésta para el Pabellón Philips.

\subsubsection{Montaje, arquitectura y revolución. Le Corbusier en la URSS}

Le Corbusier, desde su visita a Moscú en octubre de 1928, quiso vincularse con la URSS. Utilizando como medio la arquitectura, desarrollaba los mismos presupuestos que Eisenstein esbozaba y experimentaba en el cine.

\footnotetext{
${ }^{22}$ Eisenstein, Sergei: El sentido del cine. Buenos Aires: Lautaro, 1941.p.35

${ }^{23}$ Nizhny, Vladimir: Lecciones de cine de Eisenstein. Barcelona: Seix Barral, 1963.p.232

${ }^{24}$ Ibíd.p. 213

${ }^{25}$ Ibíd.p. 212

${ }^{26}$ Ibíd.p. 213

${ }^{27}$ En "Piranesi, Or The Fluidity Of Forms" en Tafuri, Manfredo: La esfera y el laberinto. Vanguardias y arquitectura.De Piranesi a los años setenta. Barcelona: Gustavo Gili, 1984.pp.99-102. También en Oppostions. A journal for Ideas and Criticism in Architecture. №11. Winter 1977. Cambrigde, MA: The MIT Press, 1977.
} 
Sin embargo, como escribe Jean-Luis Cohen, "las afinidades entre la teoría de Le Corbusier, el élan lyrique de la máquina, y Eisenstein, y el pathos de la máquina, permanecieron menos explícitas que latentes" 28 .

\section{*Defensa del Centrosoyus}

Uno de los dos puntos clave en el período en que Le Corbusier trató de vincularse a la URSS, fue la construcción del Centrosoyus (1928-35). En 1933 publicó Défense de l'Architecture ${ }^{29}$ en el número monográfico que la revista francesa L'Architecture d'aujourd'hui dedicó a su obra conjunta con Pierre Jeanneret. Entre los proyectos que aparecían estaba el Centrosoyus. La imagen de la maqueta para el edificio de las cooperativas rusas, que se mostraba en la revista, era una vista cenital que se asemejaba irónicamente a la figura de un obrero trabajando con la maquinaria. El título que la acompañaba era el de "une maison sans escaliers".

Con esta publicación Le Corbusier se defendía de los ataques de los constructivistas hacia su élan lyrique: éstos alegaban que la arquitectura debía ceñirse a la función y las verdaderas necesidades. "Le Corbusier en lugar de atender únicamente a la función, basaba su trabajo en una serie de estrategias para dotar a su arquitectura de un "valor adicional", un componente estético que podía ofrecer a los habitantes de sus edificios, un papel activo en la creación de su significado". ${ }^{30}$

\section{*La relación truncada con la URSS}

El otro punto clave para comprender el período de Le Corbusier y la URSS, es el del concurso para el palacio de los Soviets, explica Cohen, en su monografía Le Corbusier et la mysthique de l'URSS, "el fracaso del proyecto que presenta al concurso del Palacio de los Soviets, supuso el final de la identificación entre arquitectura moderna y Unión Soviética" ${ }^{\prime 1}$.

Entre las hipótesis planteadas para comprender el proyecto que se presentó, Quetglas establece una muy sustanciosa, basándose en el dibujo que realiza Le Corbusier recién llegado a Moscú en el andén de la estación, lo compara con la perspectiva que presentó al concurso, y detecta que la coincidencia más significativa entre los dos dibujos es el arco, "el collar del caballo, en el dibujo junto a un arco del triunfo, se parece sorprendentemente a lo que será el arco de hormigón del palacio de los Soviets". El arco parabólico de cuero y madera, tomado del modo local de enganchar a los caballos en Rusia, "no un arco del triunfo, una escenografía pasiva y declamatoria, sino un instrumento de trabajo y acción, una máquina de transformar el mundo" ${ }^{32}$. No parece casual que la imagen que muestra para ilustrar el collar del caballo pertenezca al filme Lo viejo y lo nuevo (1929) de Eisenstein.

\footnotetext{
28 "Still, the affinities between Le Corbusier's theory of "lyricism" of the machine and Eisenstein "pathos of the machine" remained less explicit than latent". Cohen, Jean-Louis: Le Corbusier and the mystique of the URSS. Princeton, New Jersey: Pinceton University Press, 1992.pp.48-50

${ }^{29}$ Le Corbusier: "Defense de 1'Architecture". En L'Architecture d'aujourd'hui, No10. 1933.p.105 y en Le Corbusier: El espíritu nuevo en arquitectura. En defensa de la Arquitectura. Murcia: Colegio Oficial de Aparejadores y Arquitectos Técnicos de Murcia, 1983.

${ }^{30}$ Martínez de Guereñu, Laura: Montage: "Le Corbusier y Eisenstein”. En: Massilia 2008. Anuario de estudios Lecorbusierianos. Granada: Colegio de Arquitectos de Granada, 2008.p.242-255. La autora visibiliza en éste artículo las estrategias empleadas por Le Corbusier en relación con los mecanismos montaje, en concreto el dialéctico que estudiamos aquí, y que interesa destacar por ejemplificar su materialización en la arquitectura.

${ }^{31}$ Quetglas, Josep: “Ojos que no ven. 4: los caballos”. En: Massilia 2008. Anuario de estudios Lecorbuserianos. Granada: Colegio de Arquitectos de Granda.p.280

${ }^{32}$ Ibíd.p. 285
} 
Shklovski, crítico y escritor con una gran proximidad a la mentalidad del realizador y coetáneo a él, escribe: "Los films y los libros dedicados a la nueva realidad han necesitado, para nacer, enteras décadas, pero el film de Sergei Mijailovich conseguía comunicar la fe orgullosa en el nuevo orden, en el sueño y en la posibilidad de realizarlo, ${ }^{, 33}$.

Aquello que sobre todo debió calar en Le Corbusier, es esta fuerza con la que el autor se podía comunicar con las masas a través del montaje y de la cinematografía. Este impulso se presenta en su arquitectura, y en el caso que aquí se estudia, por partida doble, a través del Pabellón Philips y el filme Poème électronique que en su interior se proyectó; ambos podrían suponer una respuesta a los presupuestos que aprendió de Eisenstein.

\subsection{Caso de estudio. Poème électronique}

Se aborda el estudio del filme Poème électronique y el contendor-substancia en el que se proyectó.

\subsubsection{El montaje oculto en el Pabellón Phillips}

El Pabellón Philips se construyó con motivo de la celebración de la Exposición Universal de Bruselas en 1958. El equipo que se formó para llevar a cabo el proyecto estaba constituido por Le Corbusier y el músico-ingeniero Iannis Xenakis, que se encargaron de su redacción y construcción; Edgar Varèse compuso la música, el editor Jean Petit se ocupó de localizar las imágenes que Le Corbusier le iba anotando en sus Carnets, y el cineasta Philippe Agostini las rodaba en 16 milímetros.

Jean Petit, en el libro Poème électronique (1958), recogió las primeras ideas que Le Corbusier tuvo sobre este proyecto: "No haré una fachada para Philips, haré un poema. Todo transcurrirá en el interior: la luz, el color, el ritmo. Puede que la única apariencia que tenga el pabellón sea la de un andamio"34; "este es el material fundamental y frágil de la exposición temporal: una botella suspendida en un andamiaje tubular,"35.

\footnotetext{
${ }^{33}$ Shklovski, Viktor: Eisenstein. Barcelona: Anagrama, 1973.

34 “Je ne ferai pas de façade Philips, je vous ferai un Poème électronique. Tout se passera à l'intérieur: son, lumière, couleur, rythme. Peut-être un échafaudage sera-t-il le seul aspect extérieur du pavillon”. Petit, Jean: Poème électronique. Paris: Editions de Minuit, 1958.p.23

35 "Le matériel fondamental et fragile de l'exposition temporaire- une bouteille suspendue à une cage d'échafaudage tubulaire”. Ibíd.p.24
} 

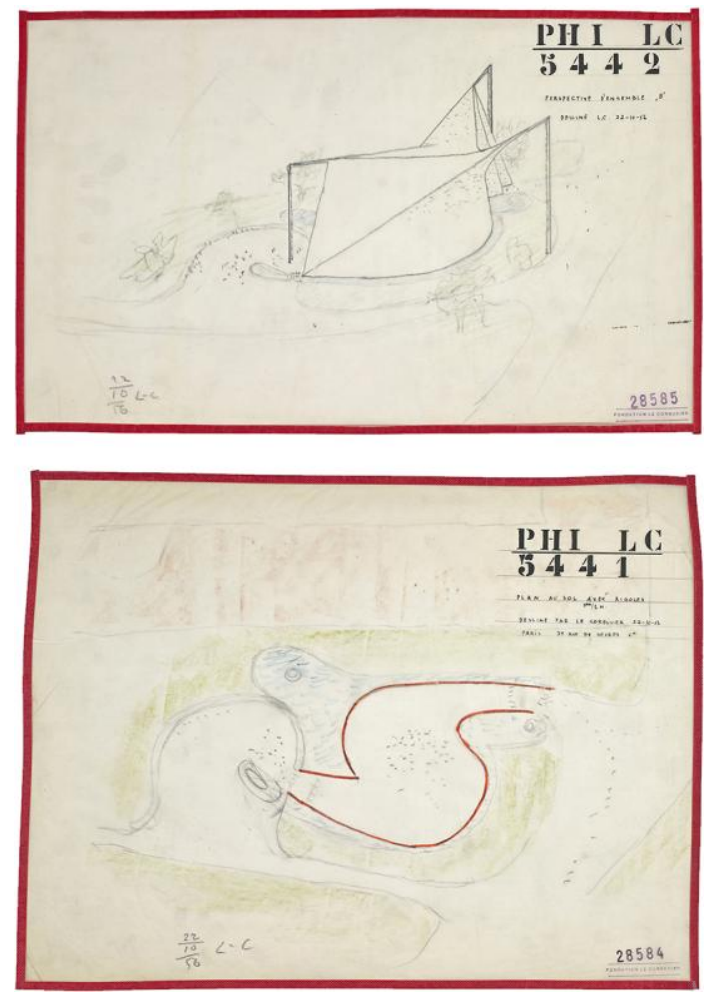

1. Planos del Pabellón Philips dibujados por Le Corbusier 22-10-1956. FLC.28584-85

Esta botella, como recipiente contenedor del espectáculo que en su interior iba a transcurrir, la describió así: "el contenedor será una especie de estómago con una entrada y una salida diferentes, para quinientas personas", un espacio en el que "el público está en pie y observa delante suyo dos paredes cóncavas prácticamente verticales que permiten a los espectadores ver por encima de las cabezas de sus vecinos" ${ }^{136}$.

Le Corbusier concibió el pabellón como una boîte à miracles, síntesis de las artes. Quesada desarrolla con profundidad esta cuestión y recoge la definición que dio de ésta en la conferencia del Théâtre Spontané en París (1948), en ella "los diversos escenarios y actores materializan el momento en que la caja mágica aparece [...] contiene todo lo que es necesario, iluminación y todos los aparatos necesarios para hacer milagros, levitación, manipulación de sonido, etc. ${ }^{\prime 37}$.

A partir de su primera intuición del Pabellón Philips, como una botella suspendida en un andamiaje metamorfoseada en estómago, Iannis Xenakis desarrolló la geometría del edificio al detalle, y se convirtió en un "caparazón matemático",38. Levantó un volumen compuesto por superficies regladas "cuya geometría inicial respondía a las leyes de la música escolástica que ya había aplicado para componer su pieza Metástasis $(1953)^{\prime 33}$.

\footnotetext{
36 "Le contenant sera une sorte d'estomac, avec une entrée et une sortie différents pour cinq cents personnes", "le public étant debout et regardant devant lui, disposer de deux parois concaves presque verticales, qui permettent aux spectateurs de voir au-dessus de la tête des voisins". Ibíd.p.24

${ }^{37}$ Quesada, Fernando: "Cajas mágicas: Le Corbusier y el Pabellón Philips". En: Massilia 2002. Anuario de estudios Lecorbuserianos. Barcelona: Caja de Arquitectos.p.181

${ }^{38}$ Xenakis, Iannis: “The Architectural Design of Le Corbsuier and Iannis Xenakis". En: Philips Technical Review. №20. pp. $2-3$

${ }^{39}$ Quesada, Fernando: “Cajas mágicas: Le Corbusier y el Pabellón Philips”. En: Massilia 2002. Anuario de estudios Lecorbuserianos. Barcelona: Caja de Arquitectos.p.187
} 
El edificio se revistió de pintura metalizada, unificando y ocultando su construcción. La carcasa conformada por una serie de superficies regladas, paraboloides hiperbólicos, se construyó con "placas de hormigón de $5 \mathrm{~cm}$ de espesor vertidas en taller, que trabajaban a compresión gracias a una serie de cables metálicos traccionados desde unos grandes puntales de hormigón in situ que actúan como estructura primaria ${ }^{, 40}$.

La cuestión clave que determina éstas decisiones formales y constructivas era la búsqueda de la eliminación de los límites físicos del pabellón, de sus paredes, haciendo del conjunto un interior puro sin exterior material alguno, es decir "diluyendo su materia constitutiva y constructiva en impresiones sensoriales tal y como reza el texto sobre L'espace indicible, redactado por Le Corbusier en $1945^{, 41}$.

En el posible guión de este proyecto los protagonistas son los visitantes constructores de un sueño que representa el Poème, proyectado en el contenedor-substancia ${ }^{42}$ que es el Pabellón Philips. La puesta en escena se desarrolla en un único emplazamiento, un espacio unitario, en el que la cámara-ojo del visitante activo que lo recorre está ante unos planos cuyos límites aparecen desdibujados, y cobra protagonismo la profundidad. El mecanismo de montaje latente en este proyecto permanece, como lo denominó Eisenstein treinta años atrás, oculto.

En palabras de Adorno, "El principio de montaje pasó al principio de construcción con una coherencia cuyos pasos tendría que escribir esa historiografía estética que todavía no existe ${ }^{, 43}$.

\subsubsection{El montaje dialéctico en el filme Poème électronique}

El Poème électronique consistía en la proyección simultánea de un documento cinematográfico sobre el interior de las paredes, esas pantallas de proyección deformada en la que las imágenes proyectadas fugaban desde la base ancha hacia el cuello de la botella, junto con la emisión de la música electrónica compuesta por Edgar Varèse a través de multitud de altavoces.

La idea inicial era "realizar una biblioteca mundial visual y sonora dentro de la botella que muestra la historia del mundo desde sus orígenes hasta la reconstrucción de la Segunda Guerra Mundial"44. Poème électronique, además de la intención enciclopedista que ilustra el curso de la civilización humana, operaba como herramienta pedagógica y redentora. La naturaleza y la cultura, lo tranquilo y lo tormentoso, el apocalipsis y la salvación.

Sobre la relación del filme y la música, el compositor explicó que "de vez en cuando se coordinarán para un efecto dramático y crear una sensación de unidad”, pero la mayor parte del tiempo trabajaron en oposición y contraste buscado "a través de la sincronización de elementos simultáneos sin relación entre ellos se producirá una disociación de ideas que excitará la imaginación y estimulara las emociones" ${ }^{45}$.

\footnotetext{
${ }^{40}$ Ibíd.p. 171

${ }^{41}$ Ibíd.p. 184

${ }^{42}$ Se denomina contenedor-sustancia en el sentido de la filosofía del quiasmo de Merleau-Ponty que defiende que la espacialidad es ontológica, y la profundidad no es puro espacio, es tiempo.

${ }^{43}$ Escrito entre 1961-1969, se publicó póstumamente en 1970. Adorno, Theodor: Teoría estética. Madrid: Akal, 2005.p.107

${ }^{44}$ Quesada, Fernando: “Cajas mágicas: Le Corbusier y el Pabellón Philips”. En: Massilia 2002. Anuario de estudios Lecorbuserianos. Barcelona: Caja de Arquitectos.p.187

${ }^{45}$ Maderuelo, Javier: Edgar Varèse. Madrid: Círculo del Bellas Artes, 1985.p.180
} 


\section{*Elementos visuales $>$ Collage multimedia}

Los elementos visuales que constituyen el Poème son:

-Écrans: Muros cóncavos/pantallas donde se proyecta el filme.

-Ambiances: Proyecciones de luces de colores.

-Tri-trous: Filtros con agujeros colocados delante de los proyectores de cine para definir aéreas perfiladas de color (o ausencia de color) en los écrans y ambiances, así como para proyectar imágenes de contorno acotado.

-Volumes: Dos sólidos tridimensionales suspendidos de dos de los vértices del pabellón. Uno era una escultura de tubos, figura geométrica matemática, y el otro un maniquí industrial, figura femenina, que iluminados con luz ultravioleta brillaban en tono verdoso y rojo respectivamente.

\section{*Elementos visuales > El filme}

El mecanismo principal que Le Corbusier empleó para construir el filme Poème électronique fue el montaje dialéctico. Le Corbusier lo aprendió a través de sus contactos con Eisenstein, treinta años atrás. En la monografía de Marc Treib sobre el Pabellón Philips, el autor cree en esta posible relación y afirma que "Le Corbusier, para su secuencia cinética de fotografías, se basó en las lecciones que Eisenstein le había enseñado"46.

La técnica del montaje dialéctico, de la que Eisenstein es el indiscutible maestro, se manifiesta evidente como herramienta clave del filme. El cineasta, en "Montaje" (1938), describió su funcionamiento así: "la representación $A$ y la representación $B$ deben buscarse de tal naturaleza que su yuxtaposición suscite en la percepción y la afectividad del espectador la imagen más completamente exhaustiva del tema",47.

Le Corbusier, ante la elección de los fotogramas que conformarían el filme, explicó “Allí, las posibilidades son casi infinitas. Pero ¿Cómo elegir? Pensé: Museo del Hombre, Palacio del Descubrimiento, Museo de Historia Natural, Museo de las Tradicionales populares. Dos meses, un año buscando "48. La gran parte serían fotografías estáticas, y muchas de ellas de los libros de esculturas de André Malraux.

Poème está estructurado en siete secuencias, cada una, de un minuto de duración aproximadamente. El cambio de una secuencia a otra no se percibe con facilidad, se diferencian mediante un breve momento de oscuridad.

^Datos técnicos:

Duración: 480”'

Fotogramas por segundo: 24

Rodada en $16 \mathrm{~mm}$

46 "Le Corbusier, for his kinetic play of photographs in Brussels, he relied on the lessons that Eisenstein had taught". Treib, Marc. Space calculated in Seconds. Princeton, New Jersey: Princeton University Press, 1996.p.147

${ }^{47}$ Eisenstein, Sergei: Reflexiones de un cineasta. Barcelona: Lumen, 1970.p.128

48 “Là, les possibilités sont presque infinies. Mais comment choisir? J'ai pensé: Musée de l'Homme, Palais de la Découverte, Muséum d'Histoire Naturelle, Musée des Traditions Populaires. Des mois, une année à chercher'. Petit, Jean: Poème électronique. Paris: Forces Vives, 1958.p.25 


\section{+Secuencia \#01: Génesis [0”-60"]}

Los fotogramas aparecen con un ritmo regular, cambian cada 5 segundos.

El primer fotograma A presenta la cabeza de un toro a la izquierda, y en el siguiente fotograma B la figura de un matador a la derecha; en el tercer fotograma $\mathrm{C}$ las dos figuras aparecen a la vez y se hace explicita la idea de combate. Se repiten los fotogramas A y B, y los siguientes muestran detalles de éstos: los cuernos del toro y el matador empuñando el capote, y de nuevo aparece el fotograma $\mathrm{C}$ en el que ambas figuras están enfrentadas.

Le Corbusier contrapone los fotogramas y hace que el visitante participe y construya en su mente la imagen que quiere transmitir, tal y como él la ha concebido. También recurre a la estrategia de la repetición y la del cambio de escala, dando una dimensión mayor a los detalles. La cuestión de los opuestos, que establece el propio tema del combate entre toro y matador, estará presente a lo largo de todo el filme.

La siguiente escena se rodó expresamente para Poème, en ella aparece el cuerpo de una mujer acostada y gira la cabeza, mira a la cámara, sonríe, y de repente le cambia la expresión y se aterroriza. Como señala Treib, esta escena nos remite al cine clásico surrealista, en particular de Luis Buñuel y La Edad de Oro (1930) ${ }^{49}$. La yuxtaposición de estos fotogramas tiene múltiples interpretaciones y precipita la imaginación del observador.
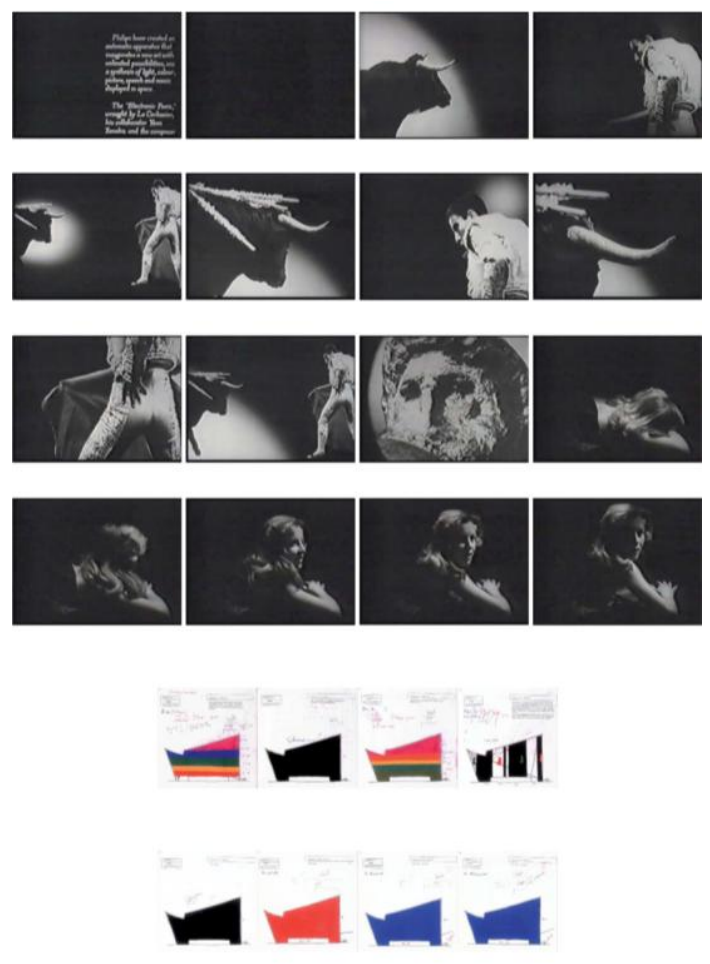

2. [Sequence I] Fotogramas extraídos de Poème électronique por la autora + Ambiances. Philips Company Archives.

\footnotetext{
${ }^{49}$ Treib, Marc. Space calculated in Seconds. Princeton, New Jersey: Princeton University Press, 1996.p.120
} 


\section{+Secuencia \#02: De la Materia y el Espíritu [61”-120”]}

Los fotogramas se muestran a un ritmo más rápido, cambian cada segundo.

La posición que ocupaba la cabeza de la mujer en la última escena de la Secuencia\#01, tras oscurecerse completamente para dar paso a esta Secuencia\#02, la va a ocupar un cráneo, y éste desaparece y reaparece de nuevo en una posición central y enfrentada al espectador; a estos fotogramas, $\mathrm{A}$ [en el lado izquierdo] y A* [enfrentado al observador], le sigue el fotograma B que muestra una concha situada donde antes estaba el cráneo, y reaparece en el fotograma $\mathrm{B}^{*}$ en posición horizontal. La muerte y la naturaleza.

En el siguiente fotograma $\mathrm{C}$ aparece un cráneo diminuto, y en el siguiente fotograma $\mathrm{D}$ vemos a 4 científicos que observan un objeto. El modo en que se muestra el fotograma D merece ser comentado, la imagen completa sólo se revela al final y se ha ido iluminando a cada uno de los personajes como si fueran fotogramas independientes: $\mathrm{D} * 1 / \mathrm{D} * 2 / \mathrm{D} * 3 / \mathrm{D} * 4 / \mathrm{D} * 5$. La muerte, la naturaleza, y la ciencia.

En el fotograma $E$ una mujer africana aparece en el centro del plano; el fotograma $F$ muestra un rostro en la parte superior derecha, y le sigue el fotograma $\mathrm{F}^{*}$ que descubre aquello que el rostro observa: el cuerpo de una mujer acostada que pertenece al cuadro de Courbet. En los siguientes fotogramas G diversos rostros de esculturas aparecen ocupando distintas zonas del plano.

En los fotogramas $\mathrm{H}$ se ilumina por partes el esqueleto de un dinosaurio. En los fotogramas I, aparecen unos monos, primero uno, luego varios, y multitud de ellos. Finaliza con los fotogramas J que muestran máscaras diversas mediante la misma estrategia: una, varias, y ocupando distintas zonas del plano.

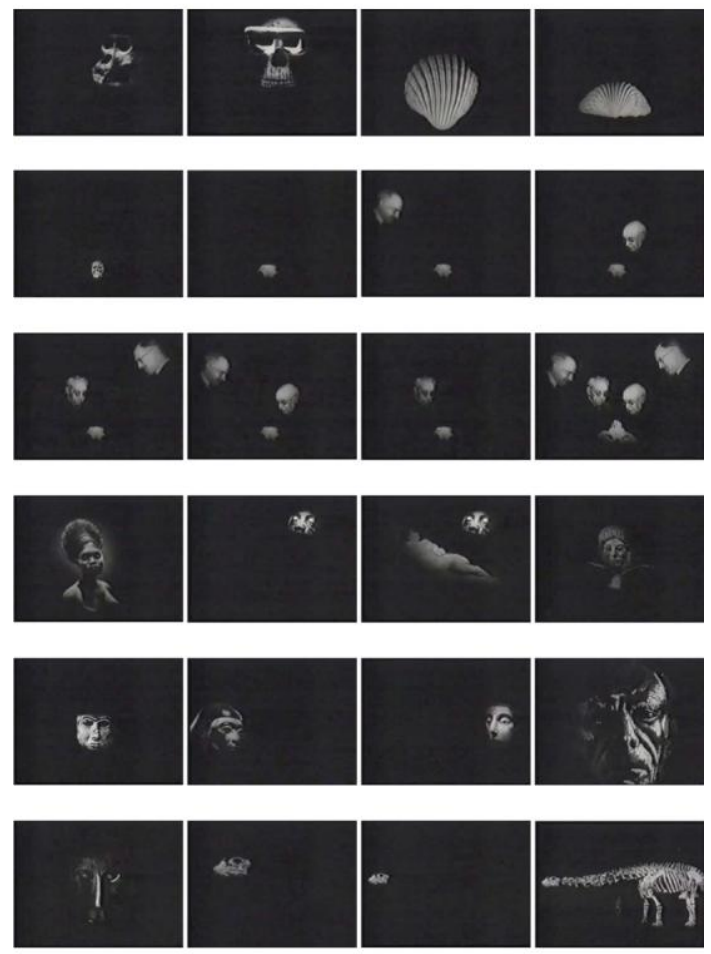

3. [Sequence II-p.1] Ibíd. 


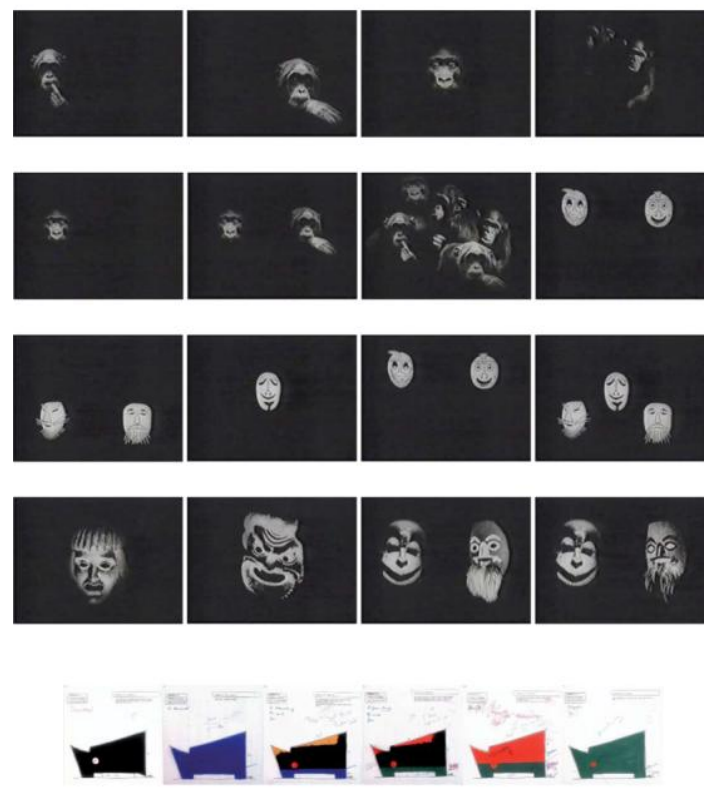

4. [Sequence II-p.2] Ibíd.

\section{+Secuencia \#03 De las Profundidades del Alba [121”-204”]}

Esta secuencia continúa con el ritmo acelerado de la anterior, apenas transcurre un segundo por cada fotograma.

Le Corbusier emplea una nueva estrategia en la primera parte, en los fotogramas $\mathrm{A} / \mathrm{B} / \mathrm{C} / \mathrm{D} / \mathrm{E}$ [con sus respectivas variaciones], consiste en la repetición del objeto representado mediante simetría en eje vertical y horizontal dramatizando así lo que se muestra, en este caso son miradas y cabezas.

Tras oscurecerse la pantalla comienza la segunda parte; el primer fotograma F se muestra por partes: primero un primer plano de las cabezas de las esculturas, dándoles una dimensión monumental, y luego un plano general que muestra las tres; juega con el cambio de escala y transmite la relatividad con que se percibe su dimensión. En los fotogramas $\mathrm{G}$ el esqueleto de la mano humana se muestra de diferentes modos.

Se vuelve a oscurecer la pantalla y comienza la tercera parte. Se repite el [f.F] de la escultura y el [f.G] del esqueleto. A continuación los fotogramas $\mathrm{H}$ muestran las zanjas abiertas de un campo de concentración y con ello la destrucción; y en el fotograma I se ven unos soldados de juguete que podría sugerir la guerra como artificio, en la que las mentes de los soldados están dominadas.

Los siguientes fotogramas muestran: la zanja de un campo de concentración [f.J], tanques de juguete [f.K], un campo de concentración [f.L], los soldados de juguete [f.I], una nueva fotografía de un campo de concentración [f.M], de nuevo los soldados de juguete [f.I], otra fotografía de un campo de concentración [f.N], unos indios y vaqueros de juguete [f.O], armas de juguete [f.P], y un primer plano de un hombre en un campo de concentración [f.L*].

Finaliza con: el Descendimiento de Giotto [f.Q], Cristo [f.R], la Natividad en Chartres [f.S], la Virgen y Niño [f.T], el Ángel [f.U], la Anunciación [f.W], Dios [f.X], la gran compasiva [f.Y], y la Virgen de los Dolores [f.Z].

Esta secuencia sugiere la confrontación entre la dimensión religiosa y la ruina de los efectos de la guerra. 

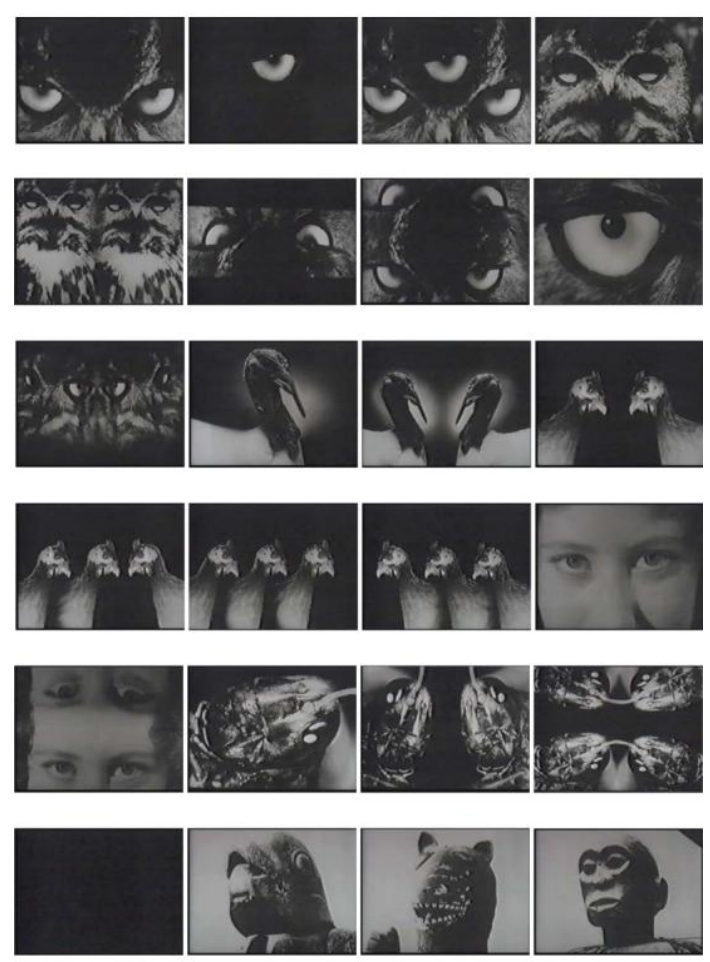

5. [Sequence III-p.1] Ibíd.
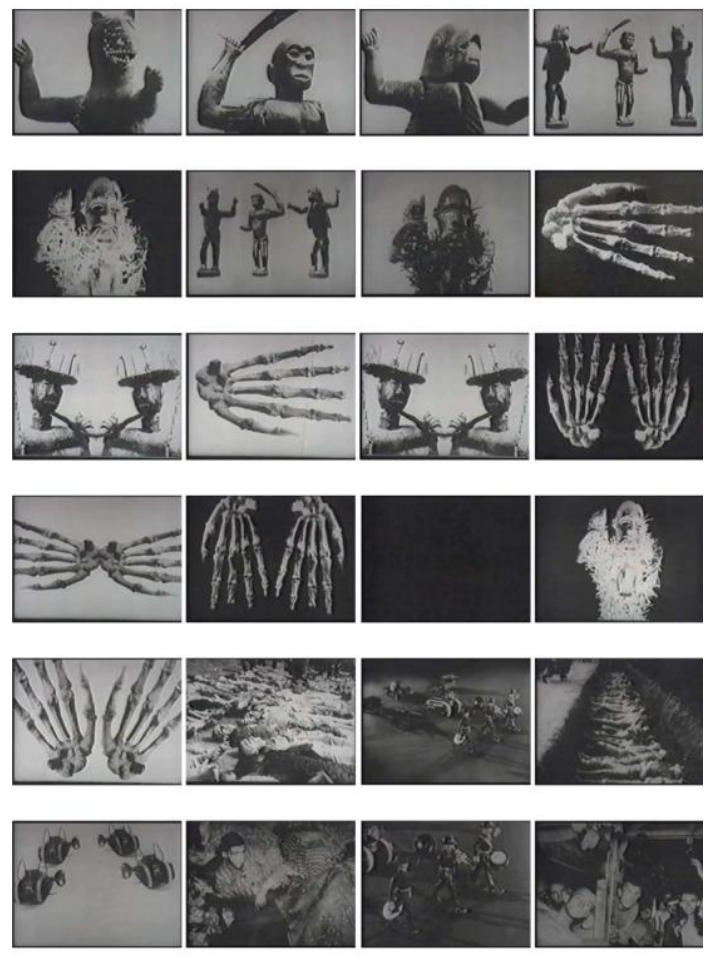

6. [Sequence III-p.2] Ibíd. 

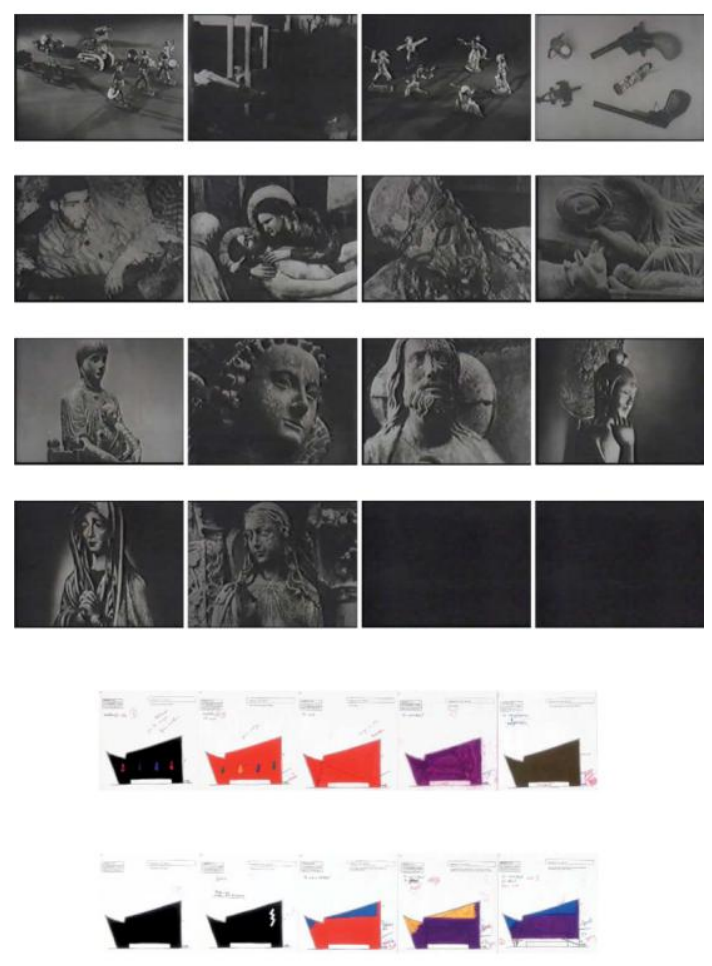

7. [Sequence III-p.3] Ibíd

\section{+Secuencia \#04: Los Dioses hechos por los Hombres [205"-240”]}

Esta es la secuencia más breve del filme; transcurren 2 segundos por cada fotograma.

Aparece en el fotograma A la Isla de Pascua, en [f.A*] sólo una de las piedras iluminada y después se repite el [f.A]. A continuación en el fotograma B se muestra la cabeza Angkor en un primer plano. En el fotograma C aparecen cuatro cubos espaciados en una superficie. Esta contraposición entre los fotogramas [f.A] y [f.C] podría sugerir el trabajo de los hombres en el planeta frente a la geometría como primacía del orden, explica Treib ${ }^{50}$.

En el fotograma D se muestra a Buda, y en el fotograma E el rostro de una Virgen. Se repite el fotograma [f.C]. En el fotograma $\mathrm{F}$ aparece una escultura tribal duplicada que coincide con la forma de los vegetales que muestra el siguiente fotograma $\mathrm{G}$, y más elementos orgánicos en [f.H]. Le siguen los fotogramas [f.D*] que muestran un detalle de [f.D], y para terminar un primer plano de una piedra de la Isla de Pascua duplicada [f.I].

\footnotetext{
${ }^{50}$ Ibíd.p. 126
} 

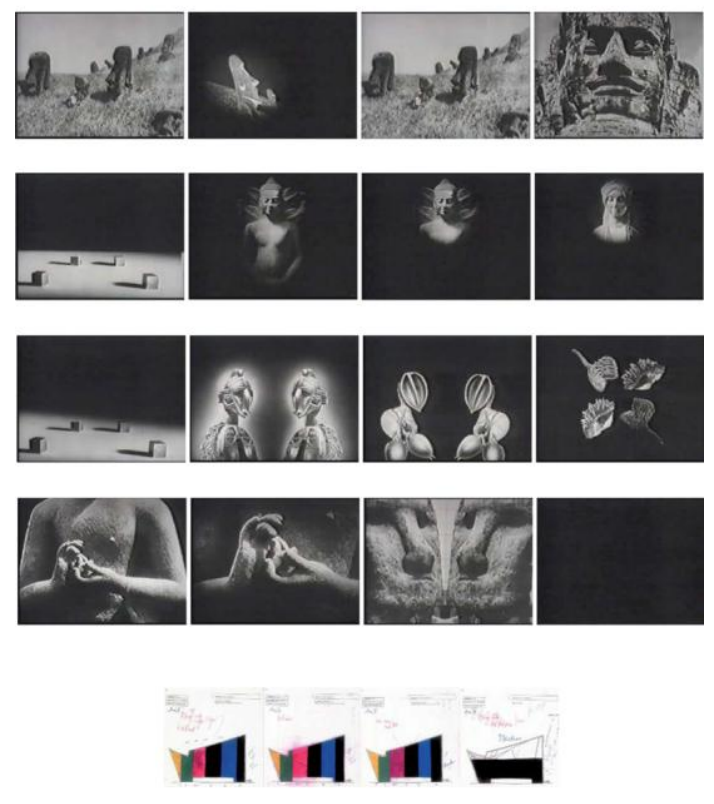

8. [Sequence IV] Ibíd.

\section{+Secuencia \#05 Así florece la Civilización [241”-300”]}

Los fotogramas cambian cada segundo y medio.

Tras 5 segundos de oscuridad aparece el fotograma A que muestra a un ingeniero atómico que está manejando la maquinaria, la estrategia que Le Corbusier emplea para revelar este fotograma es, como en ocasiones anteriores, iluminar primero sólo la cara y luego sólo la maquinaria; el movimiento de la luz consigue animar la fotografía.

En el fotograma B aparece multitud de gente. En el fotograma $\mathrm{C}$ hay un trabajador con el telescopio que observa la dimensión inmensa del cielo. El fotograma D muestra la fundición del acero, y sucesivamente: multitud de gente [f.B], la estratosfera [f.E], multitud de gente [f.B], trabajadores [f.F], cirujanos [f.G], mineros [f.H], otros trabajadores [f.I] y un labrador [f.J].

A continuación: un caballo de granja [f.K], el cómico Charlot [f.L], un avión [f.M], cohete [f.N], antenas [f.O], cohete [f.N], antenas [f.O], avión [f.M], dos niños inquietos mirando [f.P], dos cohetes [f.N*], tres niños inquietos mirando [f.Q], la antenas duplicadas [f.O*], explosiones nucleares diversas [f.R], más niños inquietos mirando [f.S], y finalmente una madeja enmarañada [f.T].

Esta secuencia muestra aquello que la humanidad también ha forjado: la industria y el poder. 

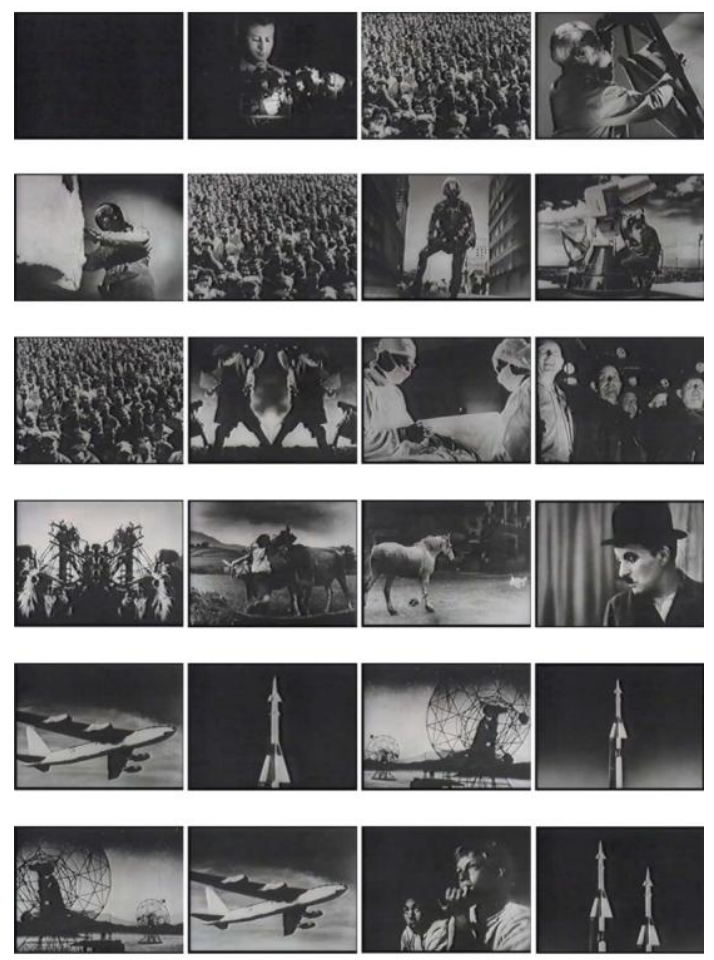

9. [Sequence V-p.1] Ibíd.
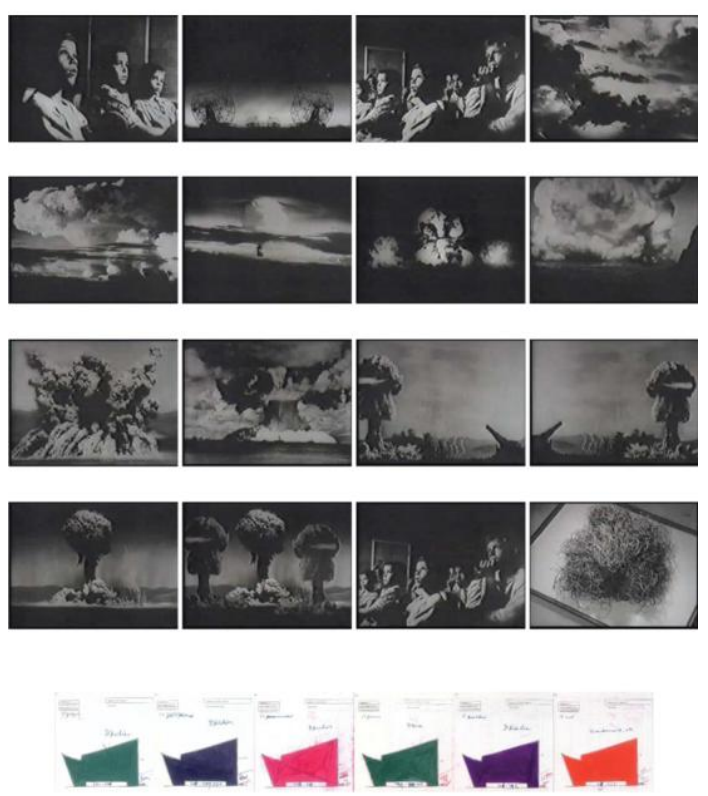

10. [Sequence V-p.2] Ibíd. 


\section{+Secuencia \#06 Armonía [301"-360"]}

Los fotogramas cambian cada segundo y medio.

En los primeros fotogramas A aparece el entramado de la Torre Eiffel y alterna su positivo y negativo. En los fotogramas B se muestran piezas mecánicas en blanco sobre un fondo negro, parece crear su propio baile mecánico, Treib ${ }^{51}$ relaciona estos fotogramas con las primeras películas de Man Ray y con el Ballet mécanique de Fernand Léger

En el fotograma $\mathrm{C}$ aparece la mirada de un búho, en el fotograma $\mathrm{D}$ la de un toro, $\mathrm{y}$ en el fotograma $\mathrm{E}$ una pieza mecánica. A continuación reaparecen fotogramas alternados con otros nuevos, en ellos se muestra: el primer plano del rostro del ingeniero atómico [f.F], varias piezas mecánicas [f.G], mineros [f.H], y de nuevo piezas mecánicas duplicadas [f.G*].

De nuevo aparece el trabajador con el telescopio [f.I], piezas mecánicas [f.G*], el trabajador [f.I] y diversos fotogramas de piezas mecánicas [f.E*/G*]. Laurel y Hardy y piezas mecánicas [f.J]. La presencia los cómicos podría sugerir la comedia como alivio, o lo absurdo del juego de la humanidad con la tecnología.

La escala cambia y los siguientes fotogramas muestran: la galaxia [f.J], eclipses solares [f.K], llamas solares [f.L]; y tras la oscuridad: dos enamorados en un banco [f.M] y abrazándose [f.N], y finaliza con bebés [f.O/P/O*/Q/O*].
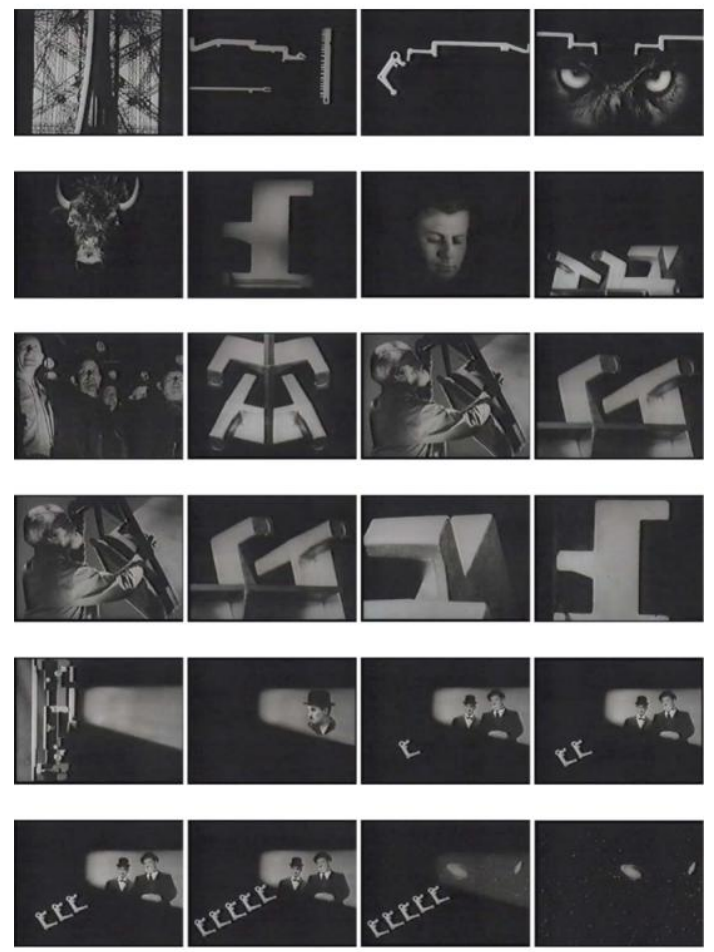

11. [Sequence VI-p.1] Ibíd.

\footnotetext{
${ }^{51}$ Ibíd.p. 134
} 

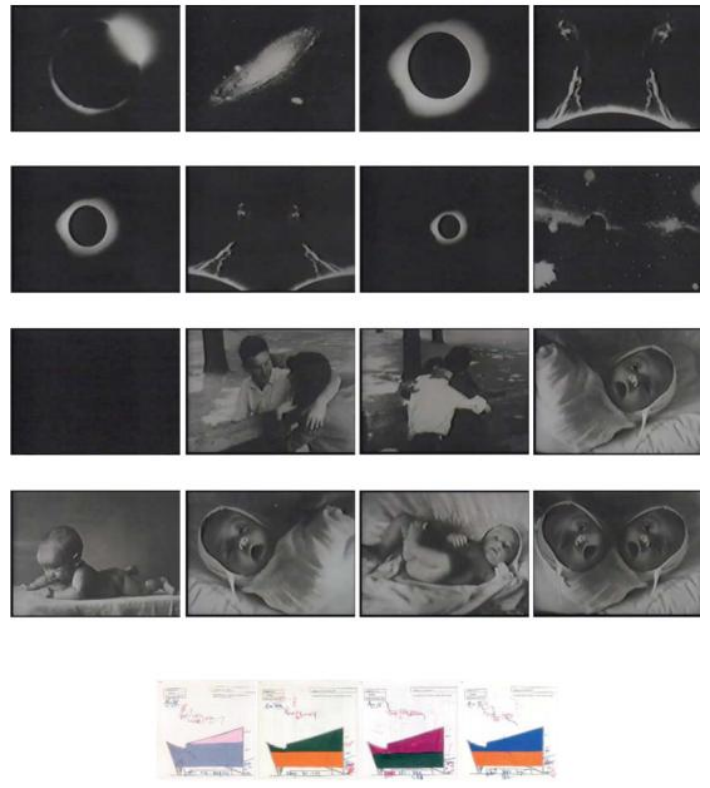

12. [Sequence VI-p.2] Ibíd.

\section{+Secuencia \#07 Para Todo el Mundo [361"-480"]}

Esta es, con diferencia, la secuencia más larga del filme; transcurre un tiempo variable según el fotograma.

Estos muestran: Los cuatro rascacielos de París [f.A], la ciudad de Nueva York [f.B], se repiten [f.A] y [f.B], diversos fotogramas de la ciudad radiante de Marsella y Nantes [f.C/D/E/F], el capitolio de Chandigarh [f.F/G/H], el modulor [f.I/J], un muro aparejado de piedra [f.K], la ciudad de Nueva York [f.L], se repiten con velocidad varias veces [f.K] y [f.L], otro aparejo [f.M], plano de París [f.N], urbanismo de Argel [f.O], las rutas de Europa [f.P].

Para terminar recupera la presencia humana: dos niños [f.Q], la mano abierta de Le Corbusier [f.R], una mujer [f.S/T/U], un niño [f.V], un vagabundo [f.W], un comedor [f.X], un camino en el barro [f.Y], los bebés [f.Z].

La relación de la música y el filme, en esta secuencia parece coincidir con la intención de enfatizar la grandiosidad de sus proyectos en contraposición con el caos de la ciudad de Nueva York.

Esta secuencia responde al objetivo de Le Corbusier de publicitar su propia obra. Si en la anterior retrata una época de caos, pobreza y reconstrucción tras la Segunda Guerra Mundial, aquí muestra su arquitectura como un motivo de esperanza para la humanidad. 

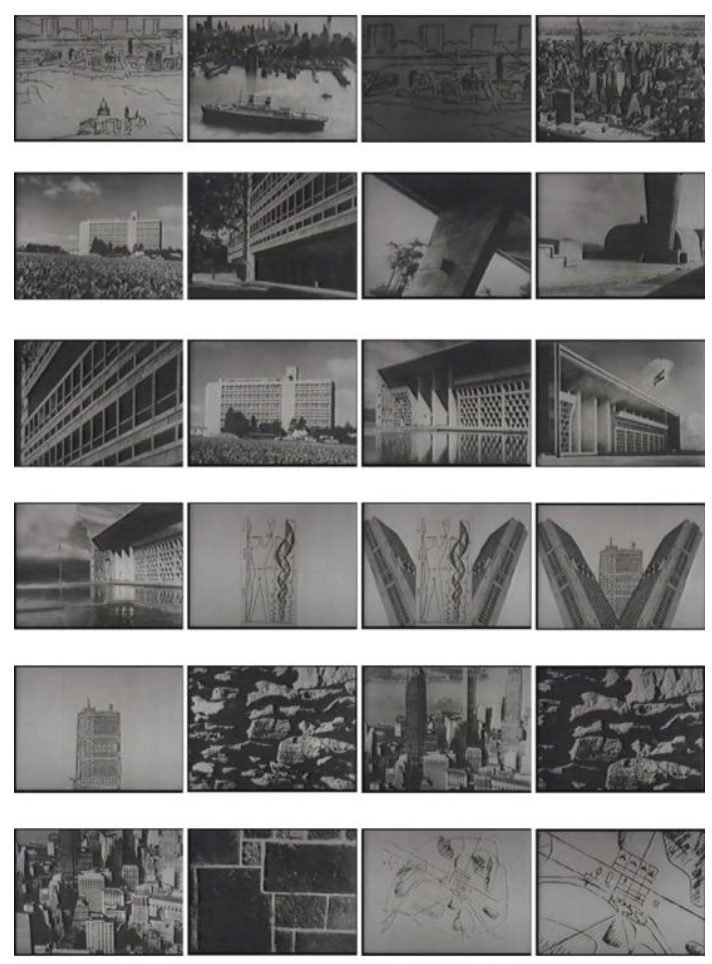

13. [Sequence VII-p.1] Ibíd.
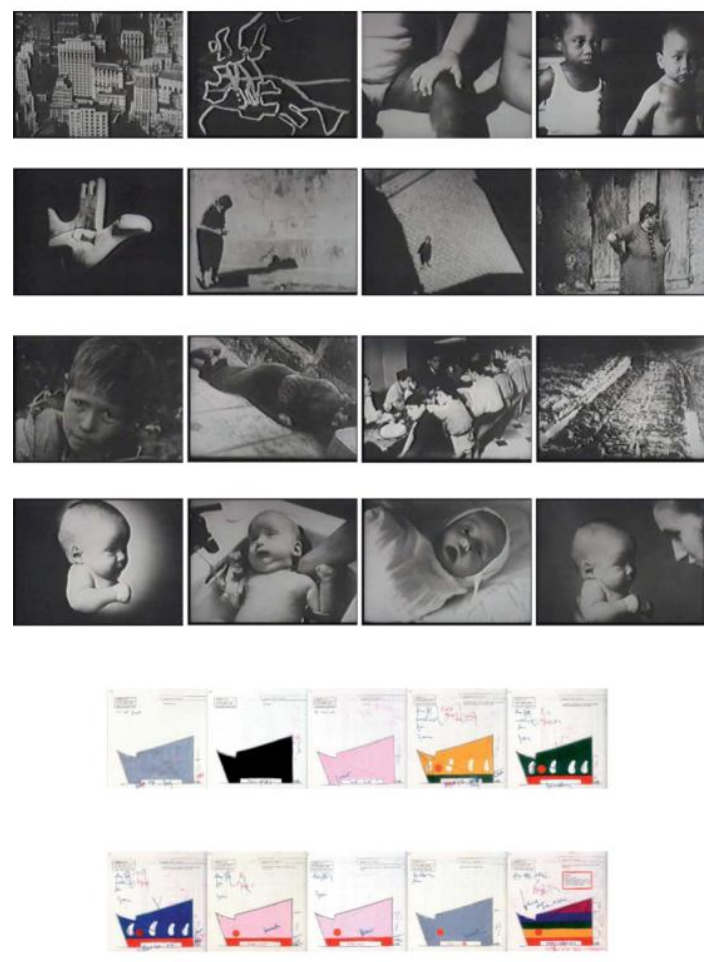

14. [Sequence VII-p.1] Ibíd. 


\section{Conclusiones}

La investigación sobre los vínculos existentes entre Eisenstein y Le Corbusier ha sido emprendido anteriormente por otros autores, sus aportaciones se incorporan al desarrollo del presente artículo y refuerzan la hipótesis planteada: el Poème électronique y el Pabellón pueden suponer una respuesta a los presupuestos que Le Corbusier aprendiera de Eisenstein.

Como describió Cohen, las afinidades entre ellos permanecieron latentes. Para visibilizarlas se estudia el estado de las teorías sobre el montaje de Eisenstein en el período en que Le Corbusier visitó Moscú y se conocieron.

En su retrato de la Historia de la humanidad, Le Corbusier transmite la fe y el sueño por un nuevo orden y la posibilidad de alcanzarlo tras la situación de crisis, pobreza y miseria fruto de la Segunda Guerra Mundial, tal y como Eisenstein consiguió con sus películas, treinta años antes, transmitiendo el éxito de las transformaciones por el cambio político fruto de la Revolución de 1917, Le Corbusier anuncia su propia arquitectura como aquella que traía orden y salvación frente a la crisis del momento.

A través de éste espectáculo da una dimensión monumental a lo esencial de lo común y dirige al visitante a través del cine y la arquitectura, mediante los mecanismos del montaje dialéctico y el montaje oculto. Es posible que el poder de comunicación de su arquitectura se base en la utilización de estos mecanismos.

Con Poème électronique y su contendor-substancia, Le Corbusier trata de representar la construcción de un sueño, y lo consigue. La técnica empleada es el montaje y el sueño la utopía del revolucionario. Le Corbusier reconoció el potencial de las teorías de montaje del cineasta, precisamente por la capacidad que tiene de activar al espectador e involucrarlo en la construcción de su significado. Las incorporó en su propio pensamiento y las materializó en su arquitectura, así como en su aproximación al ámbito de la cinematografía.

\section{Referencias bibliográficas}

Adorno, Theodor: Teoría estética. Madrid: Akal,2005.

Benjamin, Walter: El autor como productor. Madrid: Casimiro,2015.

Cohen, Jean-Louis: Le Corbusier and the mystique of the URSS. Princeton, New Jersey: Princeton University Press, 1992.

Deleuze, Gilles: La imagen movimiento. Barcelona: Paidós,2014.

Eisenstein, Sergei: El sentido del cine. Buenos Aires: Lautaro,1944.

Eisenstein, Sergei: Hacia una teoría del montaje. Vol.1. Barcelona: Paidós Ibérica,2001.

Eisenstein, Sergei: Reflexiones de un cineasta. Barcelona: Lumen,1970.

Le Corbusier: Hacia una arquitectura. Barcelona: Apóstrof,1998.

Le Corbusier: El espíritu nuevo en arquitectura. En defensa de la Arquitectura. Murcia: Colegio Oficial de Aparejadores y Arquitectos Técnicos de Murcia,1983.

Maderuelo, Javier: Edgar Varèse. Madrid: Círculo de Bellas Artes,1985.

Martínez de Guereñu, Laura: "Montage: Le Corbusier y Eisenstein". En: Massilia 2008. Anuario de estudios Lecorbusierianos. Granada: Colegio de Arquitectos de Granada,2008.

Nizhny, Vladimir: Lecciones de cine de Eisenstein. Barcelona: Seix Barral,1963.

Petit, Jean: Poème électronique. Paris: Editions de Minuit,1958. 
Quetglas, Josep: “Ojos que no ven. 4: los caballos”. En: Massilia 2008. Anuario de estudios Lecorbuserianos. Granada: Colegio de Arquitectos de Granda,2008.

Quesada, Fernando: “Cajas mágicas: Le Corbusier y el Pabellón Philips”. En: Massilia 2002. Anuario de estudios Lecorbuserianos. Barcelona: Caja de Arquitectos,2002.

Shklovski, Viktor: Eisenstein. Barcelona: Anagrama,1973.

Tafuri, Manfredo: La esfera y el laberinto. Vanguardias y arquitectura. De Piranesi a los años setenta. Barcelona: Gustavo Gili,1984.

Treib, Marc. Space calculated in Seconds. Princeton, New Jersey: Princeton University Press, 1996.

Xenakis, Iannis: “The Architectural Design of Le Corbusier and Iannis Xenakis". En: Philips Technical Review. No20. 